Graphical Abstract

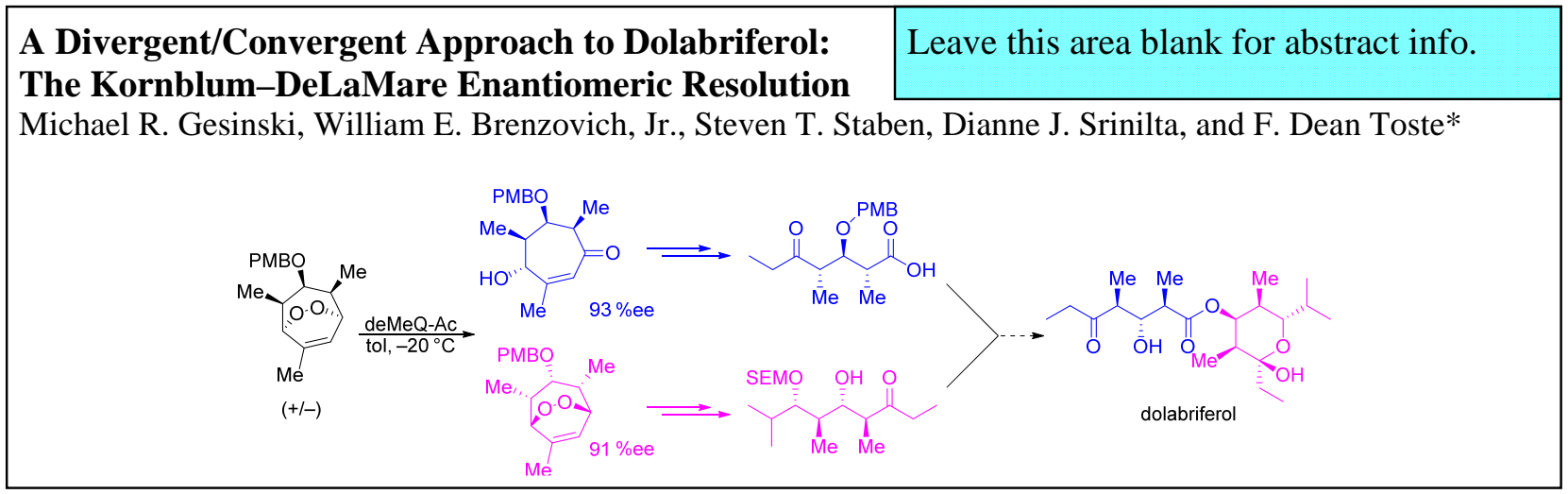


Tetrahedron Letters

journal homepage: www.elsevier.com

\title{
A divergent/convergent approach to dolabriferol: The Kornblum-DeLaMare enantiomeric resolution
}

\author{
Michael R. Gesinski, William E. Brenzovich, Jr., Steven T. Staben, Dianne J. Srinilta, and F. Dean Toste* \\ Department of Chemistry, University of California, Berkeley, CA 94720, United States
}

\section{ARTICLE INFO}

Article history:

Received

Received in revised form

Accepted

Available online

Keywords:

Convergent Synthesis

Divergent Synthesis

Kinetic Resolution

Kornblum-DeLaMare

Organocatalysis

\section{ABSTRACT}

Several protected precursors of the polypropionate metabolite dolabriferol have been synthesized. A novel Kornblum-DeLaMare enantiomeric resolution was used to form two fragments of the natural product from a common precursor.

2014 Elsevier Ltd. All rights reserved.

\section{Introduction}

Dolabriferol (1) was isolated from the acetone extracts of the sea hare, Dolabrifera dolabrifera, collected off the coast of Cuba in 1996 by Gavagnin and coworkers. ${ }^{1} \quad$ The structure was determined by advanced NMR studies and single-crystal X-ray analysis. The absolute configuration was assigned in 2010 by total synthesis ${ }^{2}$ and, later confirmed by chiral lanthanide shift reagents. ${ }^{3} \quad$ The paucity and instability of the natural product have prevented extensive biological screening, but preliminary results by Rodríquez and coworkers have produced no positive results. $^{3}$

The structure of dolabriferol is comprised of a noncontiguous carbon skeleton: two polypropionate subunits joined by an ester linkage. This unusual structural motif ${ }^{4}$ has inspired three attempted syntheses ${ }^{5}$ and two total syntheses., ${ }^{2,6}$, Most recently Goodman and coworkers have employed a late-stage acidcatalyzed retro-Claisen rearrangement to form the ester linkage from a contiguous polyproprionate chain. This fragmentation supports speculation that structures like dolabriferol may be artifacts of the isolation process and not actual natural products. ${ }^{4 a}$

Our interest in this molecule stemmed from its psuedo-dimeric nature; the two fragments, $\mathbf{2}$ and $\mathbf{3}$, contain an anti/anti stereotriad at C4-C8 and C13-C17 respectively (Scheme 1). Recently, we have disclosed an enantioselective desymmetrization reaction of endoperoxides using a KornblumDeLaMare rearrangement has furnished similar stereotriads. ${ }^{7}$ We hoped to expand this methodology to include an enantiomeric resolution by employing a racemic endoperoxide. The resolved starting material and product could then both be used to form fragments $\mathbf{2}$ and $\mathbf{3}$ of the natural product. To this end, compound $\mathbf{6}$ was identified as the ideal precursor, containing the framework necessary to furnish both halves of dolabriferol. This strategy is first enantiodivergent and second, enantioconvergent. ${ }^{8}$ Resolved starting material $\mathbf{4}$ and product $\mathbf{5}$ would be independently elaborated and reunited at the end of the synthesis. Notably, the resolution would furnish the absolute configuration of seven of the eight stereocenters in the natural product.
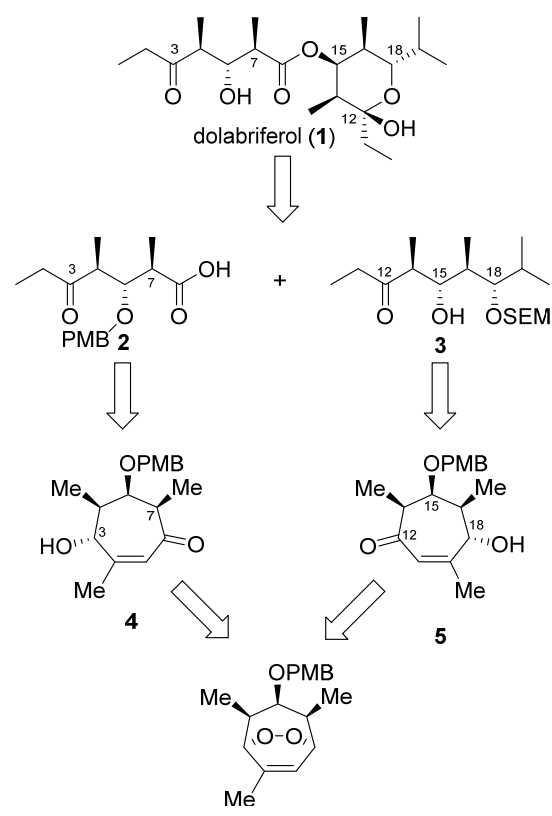

Scheme 1. Retrosynthesis. 


\section{Results and Discussion}

The synthesis of racemic endoperoxide 6 was accomplished in six steps. Diene 9 was synthesized in four steps from 3pentanone and furan using a procedure reported by Lautens and Gajda (Scheme 2). ${ }^{9}$ Protection of the hindered alcohol proved difficult and only potassium bases afforded PMB-ether $\mathbf{1 0}$. Additionally, the diene was prone to isomerization upon purification. Fortunately, [4 +2$]$ addition of singlet oxygen to the crude mixture afforded endoperoxide $\mathbf{6}$ as a single diastereomer in good yield.

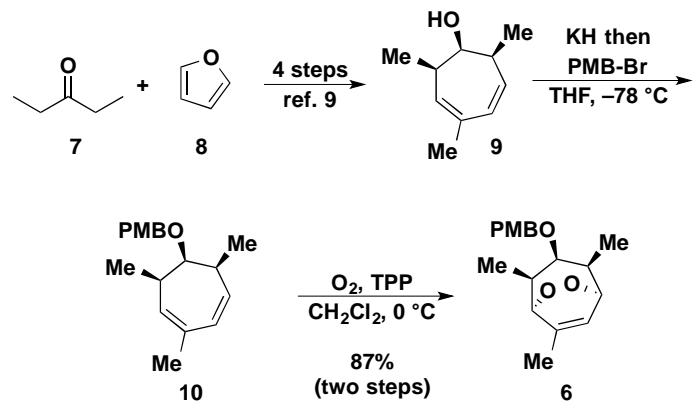

Scheme 2. Synthesis of the racemic endoperoxide.

With the requisite endoperoxide (6) in hand, attention was given to the key Kornblum-DeLaMare kinetic resolution. Initial experiments were performed on benzyl-ether $\mathbf{1 1}$ even though PMB-ether 6 was ultimately utilized in the synthesis. In order to achieve the desired selectivity, the reported conditions for the desymmeritization were modified by lowering the temperature and increasing the reaction time. ${ }^{7}$ Use of des-methyl quinidine acetate (deMeQD-Ac) afforded good conversion and moderate enantioselectivities of ketone 13, but produced a significant amount of an undesired regioisomer 15 (Table 1, entry 1). A variety of quinidine- derived base catalysts were screened, but all other catalysts either gave poor conversion (entry 2), poor enantioselectivity (entry 3), or an increase in regioisomer production (entry 4). Gratifyingly, the psuedo-enantiomeric quinine-derived catalyst (deMeQ-Ac 12) provided the opposite enantiomer with comparable efficiency (entry 5). Solvent polarity proved to have dramatic effects on the efficacy of the resolution. Polar aprotic solvents, such as THF, retarded the

Table 1. Kornblum-DeLaMare kinetic resolution.
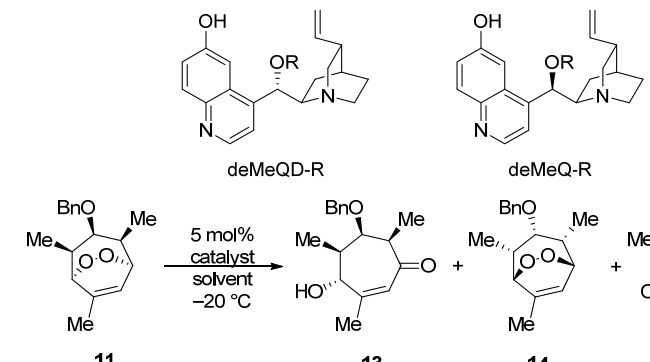

$\mathrm{BnO}$

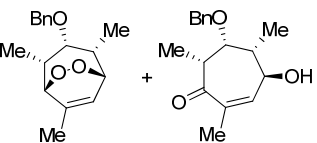

\begin{tabular}{ccccccc} 
& & \multicolumn{1}{c}{$\mathbf{1 3}$} & & $\mathbf{1 4}$ & \multicolumn{2}{c}{$\mathbf{1 5}$} \\
\hline entry & catalyst & solvent & time & $\% 13$ & $\%$ ee & $\% \mathbf{1 5}$ \\
\hline 1 & deMeQD-Ac & $\mathrm{CH}_{2} \mathrm{Cl}_{2}$ & $60 \mathrm{~h}$ & $49 \%$ & $-81 \%$ & $14 \%$ \\
2 & deMeQD-H & $\mathrm{CH}_{2} \mathrm{Cl}_{2}$ & $60 \mathrm{~h}$ & $16 \%$ & $-85 \%$ & $4 \%$ \\
3 & deMeQD-TBS & $\mathrm{CH}_{2} \mathrm{Cl}_{2}$ & $16 \mathrm{~h}$ & $49 \%$ & $-49 \%$ & $1 \%$ \\
4 & deMeQD-Bn & $\mathrm{CH}_{2} \mathrm{Cl}_{2}$ & $60 \mathrm{~h}$ & $52 \%$ & $-80 \%$ & $24 \%$ \\
5 & deMeQ-Ac (12) & $\mathrm{CH}_{2} \mathrm{Cl}_{2}$ & $60 \mathrm{~h}$ & $54 \%$ & $75 \%$ & $13 \%$ \\
6 & deMeQ-Ac & $\mathrm{THF}^{2}$ & $14 \mathrm{~h}$ & $29 \%$ & $93 \%$ & $2 \%$ \\
7 & deMeQ-Ac & iPrOH & $14 \mathrm{~h}$ & $41 \%$ & $85 \%$ & $5 \%$
\end{tabular}

deMeQ-Ac toluene $\quad 14 \mathrm{~h} \quad 45 \% \quad 93 \% \quad 4 \%$

reaction significantly (entry 6), while polar protic solvents decreased formation of the undesired regioisomer (entry 7). Ultimately, toluene proved to be the optimal solvent for the reaction, providing good selectivity and conversion (entry 8). While non-polar solvents provided optimal yield and selectivity for this reaction, there is a fine balance, as the catalyst is only sparingly soluble in toluene.

Next, the enantio-enriched product and starting material were elaborated to make fragments $\mathbf{2}$ and $\mathbf{3}$ of dolabriferol. Upjohn dihydroxylation of alkene $\mathbf{4}$ and subsequent oxidative cleavage lead to loss of formic acid and the formation of lactone $\mathbf{1 6}$ (Scheme 3). ${ }^{10}$ While this lactone contains the desired carbon skeleton of carboxylic acid 2, attempts at deoxygenation of the ketone were fruitless. Instead, reduction of compound $\mathbf{1 6}$ to the corresponding triol followed by oxidative cleavage furnished lactol 17 in good yield. Grignard addition produced diol 18 which was oxidized to yield carboxylic acid $\mathbf{2}$.

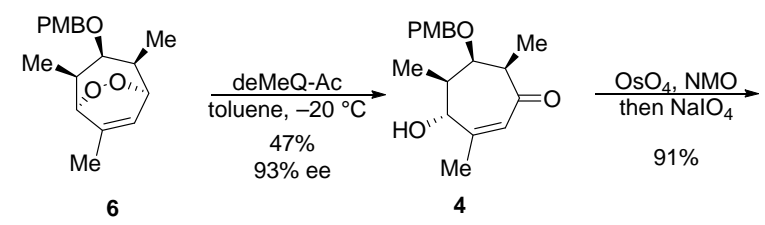

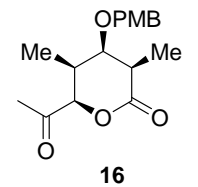
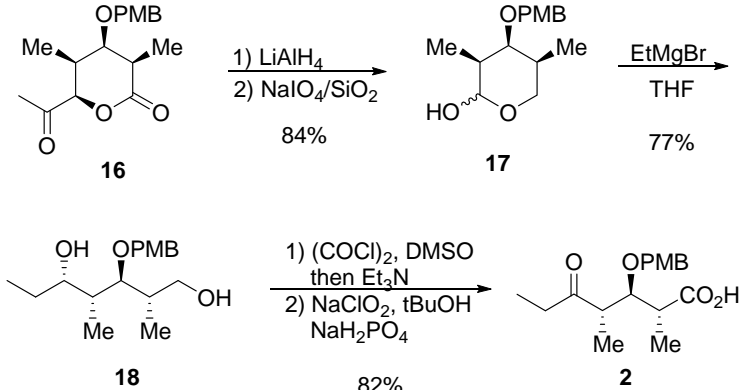

Scheme 3. Synthesis of carboxylic acid 2.

Synthesis of the alcohol fragment proved less straightforward (Scheme 4). Initially, Mitsunobu reaction with $p$-nitrobenzoic acid afforded the inversion product $19 .{ }^{11}$ Upjohn dihydroxylation and oxidative cleavage produced carboxylic acid $\mathbf{2 0}$ in quantitative yield. The acid was prone to eliminate under basic conditions so an excess of $\mathrm{N}, \mathrm{O}$-dimethylhydroxylamine hydrogen chloride was necessary for formation of the Weinreb amide. Hydrolysis of the benzoate provided alcohol 21 which was protected as a SEM-ether. The ketone was readily converted into olefin 22 by a Wittig reaction followed by addition of ethyl Grignard. In situ formation of more reactive diethylmagnesium was necessary for the success of this addition. Finally, simultaneous olefin hydrogenation and hydrogenolysis of the PMB-ether afforded alcohol $\mathbf{3}$ in good yield. 

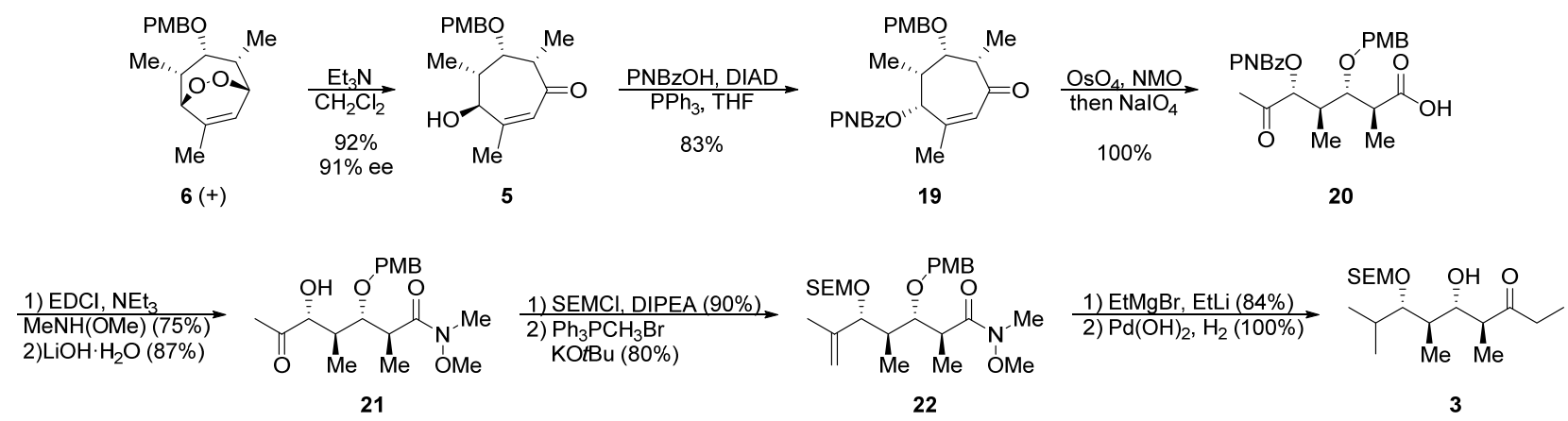

Scheme 4. Synthesis of alcohol 3.

With both fragments in hand, the final coupling and completion of dolabriferol was explored (Scheme 5). The hindered nature of alcohol $\mathbf{3}$ necessitated the use of Yamaguchi esterification conditions for the coupling with carboxylic acid $2 .{ }^{12}$ During this process, racemization of the C4 stereocenter was observed producing an inseparable mixture of diastereomers ( 10:1, 23). Fortuitously, removal of the remaining pmethoxybenzyl ether allowed for facile separation and compound $\mathbf{2 4}$ was isolated as a single diastereomer.

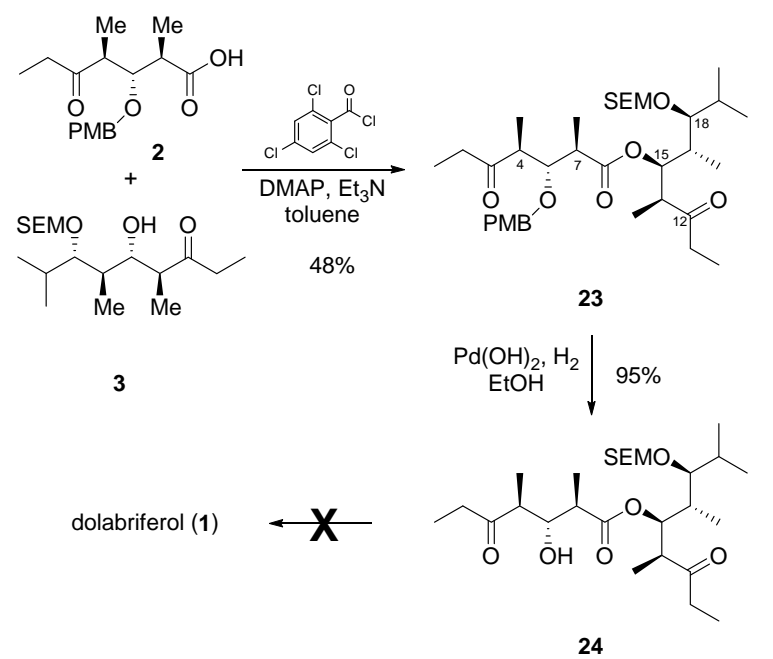

Scheme 5. Attempted completion of dolabriferol.

Perkins and coworkers previously reported difficulty in the deprotection of the TBS variant of compound 24, observing either no reaction, elimination of the ester, or rearrangement. ${ }^{5 c}$ This problem is attributed to a highly hindered silyl ether and the molecules latent sensitivity to both acidic and basic conditions. Indeed, this final deprotection is the reason for a 14 year gap between isolation and synthesis of this elusive natural product. It was hypothesized that the SEM-ether would alleviate the problem by moving the active site of deprotection away from the polyacetate backbone of the molecule, thereby allowing milder conditions for the final step. When compound $\mathbf{2 4}$ was subjected to a variety of standard and more atypical conditions, either elimination or no reaction was observed. Subsequently, TBS, TES, and BOM variants have been synthesized, but none have led to the desired natural product.

\section{Conclusion}

In conclusion, a unique divergent/convergent strategy has been implemented in the attempted synthesis of dolabriferol.

While completion of the natural product is ongoing, this method allowed for rapid synthesis of the molecule's backbone, providing seven of eight stereocenters in one step. Additionally, it provided an opportunity to develop a Kornblum-DeLaMare enantiomeric resolution. Future work will focus on utilizing this new methodology and the divergent/convergent strategy in the construction of complex organic molecules.

\section{Acknowledgments}

We gratefully acknowledge the University of California, Berkeley, and the NSF (CHE-0449449) for generous support of the work

\section{References and notes}

1. Ciavatta, M. L; Gavagnin, M. ; Puliti, R.; Cimino, G.; Martinez, E.; Ortea, J.; Mattia, C. A. Tetrahedron 1996, 52, 12831-12838.

2. Laclef, S.; Turks, M.; Vogel, P. Angew. Chem. Int. Ed. 2010, 49, 8525-8527.

3. Jiménez-Romero, C.; González, K.; Rodríquez, A. D. Tetrahedron Lett. 2012, 53, 6641-6645.

4. Similar natural products include (a) the baconipyrones: Manker, D. C.; Faulkner, D. J.; Stout, T.J.; Clardy, J. J. Org. Chem. 1989, 54, 5371-5374. and (b) siserrone A: Brecknell, D. J.; Collett, L. A.; Davies-Coleman, M. T.; Garson, M. J.; Jones, D. D. Tetrahedron 2000, 56, 2497-2502.

5. (a) Dias, L. C.; de Sousa, M. A. Tetrahedron Lett. 2003, 44, 56255628. (b) Chênevert, R.; Courchesne, G.; Caron, D. Tetrahedron: Asymmetry 2003, 14, 2567-2571. (c) Lister, T.; Perkins, M. V. Org. Lett. 2006, 8, 1827-1830. (d) Pelchat, N.; Caron, D.; Chênevert, R. J. Org. Chem. 2007, 72, 8484-8488.

6. Currie, R. H.; Goodman, J. M. Angew. Chem. Int. Ed. 2012, 51, 4695-4697.

7. Staben, S. T.; Linghu, X.; Toste, F. D. J. Am. Chem. Soc. 2006 128, 12658-12659.

8. Radosevich, A. D.; Chan, V. S.; Shih, H.-W. Angew. Chem. Int. Ed. 2008, 47, 3755-3758.

9. Lautens, M.; Gajda, C. Tetrahedron Lett. 1993, 34, 4591--4594.

10. VanRheenen, V.; Kelly, R. C.; Cha, D. Y. Tetrahedron Lett. 1976, 17, 1973-1976.

11. Inversion was confirmed through cleavage of the benzoate and spectral comparison to ketoalcohol 5.

12. Inanaga, J.; Hirata, K.; Saeki, H.; Katsuki, T.; Yamaguchi, M. Bull. Chem. Soc. Jpn. 1979, 52, 1989-1993. 